\title{
Lung function by tidal breathing in awake healthy newborn infants
}

\author{
K.C. Lødrup Carlsen*†, P. Magnus ${ }^{\dagger}, \mathrm{K}-\mathrm{H}$. Carlsen**
}

Lung function by tidal breathing in awake healthy newborn infants. K.C. Lфdrup Carlsen, P. Magnus, K-H. Carlsen. OERS Journals Ltd 1994.

ABSTRACT: The increasing availability of appliances for measuring lung function in infants may allow clinical and epidemiological applications. The aim of the present study was to establish reference values for tidal breathing lung function in awake newborn infants and to investigate potential sources of variability.

Tidal flow-volume loops were measured in 803 awake, healthy infants (427 males and 376 females) and passive respiratory mechanics (single-breath occlusion technique) in 664. Mean postnatal age was $2.7 \pm 0.9$ (sD) days, gestational age $39.8 \pm 1.4$ weeks and birthweight $3.59 \pm 0.49 \mathrm{~kg}$.

Tidal expiratory volume (VT), peak tidal expiratory flow (PEF), and mid-expiratory flow increased significantly with increasing birthweight. Flow ratios: ratio of time to PEF to total expiratory time (TPEF/TE), ratio of volume to PEF to total expiratory volume $(\mathrm{VPEF} / \mathrm{VE})$; and ratio of tidal flow at $25 \%$ remaining expiration to PEF $\left(\mathrm{TEF}_{25} / \mathrm{PEF}\right)$, were highest in 1 day old infants (medians $0.39,0.46$ and 0.81 respectively), decreasing to a minimum in 4-5 day old infants, but were not influenced by birthweight. Tidal flows and flow ratios were higher in males versus females, even after weight adjustment. Respiratory rates correlated significantly with tidal flows $(r=0.66)$, inversely with $V_{T}(r=-0.40)$, but not with flow ratios. Mean compliance of the respiratory system was $1.18 \mathrm{ml} \cdot \mathrm{cmH}_{2} \mathrm{O}^{-1} \cdot \mathrm{kg}$ birthweight $(95 \%$ confidence interval $(95 \% \mathrm{CI}) \mathrm{1.15}-1.21)$ and mean resistance $0.051 \mathrm{cmH}_{2} \mathrm{O} \cdot \mathrm{ml}^{-1 \cdot} \cdot \mathrm{s}(95 \% \mathrm{CI}$ 0.049-0.054).

These results demonstrate that lung function in awake healthy infants varies according to weight, gender and postnatal age. The present data may serve as a basis for reference values to be used in cross-sectional and prospective studies. Eur Respir J., 1994, 7, 1660-1668.

\author{
*Paediatric Dept, Ullevål Hospital, Oslo, \\ Norway. 'Dept of Epidemiology, National \\ Institute of Public Health, Oslo, Norway. \\ **Voksentoppen Centre for children with \\ asthma and allergy, Ullveien 14 , Oslo, \\ Norway. \\ Correspondence: K.C. Lødrup Carlsen \\ Paediatric Dept \\ Ullevål Hospital \\ N 0407 Oslo \\ Norway
}

Keywords: Awake healthy neonates passive respiratory mechanics percentiles

tidal flow volume

Received: December 301993

Accepted for publication May 181994

This study was supported by grants from the Norwegian Research Council.
Controversies regarding measurements of lung function in infants are partly due to unsolved questions of potential sources of variability, as pointed out in a recently published statement from the joint Committee of the European Respiratory Society (ERS) Paediatric Assembly and the ATS Assembly on Paediatrics [1]. The relative effects of arousal state, gestational age, weight and position during testing have not yet been adequately defined. Furthermore, reference values of lung function must be established with any given method in a large population of healthy subjects, before values which may be predictive of respiratory disease, or abnormality of lung function can be identified. An extensive review of the literature from 1950 to 1989 of studies describing reference values of a number of lung function parameters was published in 1989 [2].

Since that time, new commercially available appliances for measuring tidal breathing parameters and lung mechanics have attracted increasing interest. However, with the exception of tidal volume and peak tidal flow [3], reference values for such variables are scarce, and only a few studies of measurements in awake infants have been published [4, 5]. Ethically, to save time and for safety reasons, it would be beneficial to measure awake rather than sedated infants (as generally recommended if natural sleep is inadequate) [6]. Furthermore, measurements of tidal breathing and passive respiratory mechanics seem to be as reliable in infants when awake as when asleep [4]. Thus, with the increasing availability of appliances for measuring tidal breathing parameters, lung function may be measured in large populations of awake healthy and sick subjects. A previous study of tidal breathing throughout the first 5 days of life in 24 healthy awake infants, suggested that tidal flow measurements could be performed reliably from day one to four of life, whereas passive respiratory mechanics could be performed from day two to four of life, day zero being the day of birth [5].

The present study, therefore, aimed to describe lung function in normal, healthy, awake neonates measured as early as possible in their life, and to determine the relative effects of some of the possible sources of variability 
upon tidal breathing lung function. This would serve as a basis for evaluation of the distribution of normal lung function in a clinical setting, as well as in a prospective epidemiological study to investigate the possible predictive value of neonatal lung function for later respiratory disease.

\section{Material and methods}

\section{Study design}

The Environment and Childhood Asthma Study is a prospective cohort study, including a nested case control design, with the purpose of investigating the association between environmental factors, including pollution, and the development of childhood asthma. Recruitment to the study started January 1, 1992 and ended March 9, 1993. Each child will be followed for a period of 2 yrs. Inclusion criteria in the cohort were: birth weight of minimum 2,000 g; home address in the township of Oslo; no serious illness which might impair respiration (severe respiratory, cardiovascular, neuromuscular or metabolic disease); no assisted ventilation or oxygen therapy required after $6 \mathrm{~h}$ of life; and minimum parental language under-standing, sufficient to answer extensive question-

Table 1. - Distribution of age at measurement and gender for 803 healthy infants in Oslo in 1992

\begin{tabular}{lrr}
\hline & $\mathrm{n}$ & $\%$ \\
\hline Days after birth $(\mathbf{n = 8 0 1})$ & & \\
1 & 21 & 2.6 \\
2 & 354 & 44.2 \\
3 & 319 & 39.8 \\
4 & 84 & 10.5 \\
5 & 12 & 1.5 \\
$6-9$ & 11 & 1.4 \\
\hline Gender $(\mathbf{n = 8 0 3 )}$ & & \\
Boys & 427 & 53.1 \\
Girls & 376 & 46.9 \\
\hline
\end{tabular}

Table 2. - Demographic details of the 803 healthy infants in Oslo 1992

\begin{tabular}{lcccc}
\hline Variable & Mean & $(\mathrm{SD})$ & Range & $\mathrm{n}$ \\
\hline $\mathrm{VT} \mathrm{\textrm { } \mathrm { ml }}$ & 24.8 & $(4.6)$ & $13-47$ & 802 \\
$\mathrm{PEF} \mathrm{ml} \cdot \mathrm{s}^{-1}$ & 66.4 & $(17.5)$ & $18.3-130.7$ & 802 \\
$\mathrm{TEF}_{50} \mathrm{ml} \cdot \mathrm{s}^{-1}$ & 61.6 & $(16.8)$ & $18-127$ & 802 \\
$\mathrm{TPEF} / \mathrm{TE}$ & 0.32 & $(0.11)$ & $0.05-0.86$ & 802 \\
$\mathrm{VPEF} / \mathrm{VE}$ & 0.37 & $(0.10)$ & $0.07-0.84$ & 802 \\
$\mathrm{TEF}_{25} / \mathrm{PEF}$ & 0.74 & $(0.11)$ & $0.14-1.00$ & 801 \\
$\mathrm{Crs} \mathrm{ml} \cdot \mathrm{cmH}_{2} \mathrm{O}^{-1} \cdot \mathrm{kg}$ & 4.13 & $(1.19)$ & $1.04-9.03$ & 678 \\
$\mathrm{Rrs} \mathrm{cmH} \mathrm{O}_{2} \cdot \mathrm{ml}^{-1} \cdot \mathrm{s}$ & 0.051 & $(0.03)$ & $0.015-0.448$ & 678 \\
$f$ breaths $\cdot \mathrm{min}^{-1}$ & 58.9 & $(14.0)$ & $25-114$ & 802 \\
Birth weight kg & 3.57 & $(0.49)$ & $2.04-5.20$ & 802 \\
Birth length cm & 50.1 & $(2.0)$ & $43-56$ & 740 \\
Gestational age weeks & 39.8 & $(1.3)$ & $34-42$ & 700
\end{tabular}

VT: tidal expiratory volume; PEF: peak tidal expiratory flow; $\mathrm{TEF}_{50}$ : tidal mid-expiratory flow; TPEF/TE: ratio of time to reach PEF to total expiratory time; VPEF/VE: ratio of volume to reach PEF to total expiratory volume; $\mathrm{TEF}_{25} / \mathrm{PEF}$ : ratio of tidal flow at $25 \%$ remaining expiration to PEF; CRS: compliance of the respiratory system; Rrs: resistance of the respiratory system; $f$ : respiratory frequency. naires. Invitation to enrol in the project was extended to all eligible mothers at the maternity units in the two municipal hospitals of Oslo.

Throughout 1992, lung function measurements were performed at one maternity unit before the infants left the hospital. To avoid moving the fairly large testing equipment between geographically separated wards, a single unit (the larger of the two) was chosen for including and measuring infants. Due to the hospital organization, all infants delivered vaginally without major complications to mother or infant(s), were transferred to this unit, and all infants were generally healthy. All mothers in this unit were invited to enrol their infant(s) in the project. Lung function was measured in as many infants as possible during the day, restricted only by the time available. Thus, no selection bias for measurements occurred.

\section{Subjects}

Eight hundred and three subjects, 427 males and 376 females, with a mean postnatal age of 2.7 days were included into the study. Tidal flow volume (TFV) measurements were performed in 803 infants. Passive occlusion measurements were performed after TFV measurements. As the time for testing could vary from approximately 10 to $30 \mathrm{~min}$, depending upon the time to get the infant relaxed and comfortable, some of the infants would fall asleep, become hungry or unco-operative when measurements of passive respiratory mechanics should have been performed. Passive occlusion measurements were, therefore, performed in 664 infants (360 males and 304 females). All infants in the study had either TFV loops, passive occlusion measurements, or both types of measurements performed. In one infant, passive occlusion was stored before acceptable TFV loops were recorded, and the infant would not co-operate thereafter. Table 1 gives the distribution of gender and age in the sample and shows that the majority of infants were tested on days 2 and 3 after birth. Eleven infants were measured between six and nine days of age, due to admission to the neonatal unit for conditions unrelated to the respiratory system. Demographic details of the subjects are given in table 2. The infants were all without signs of respiratory disease at the time of testing, but neonates with rapid respiratory rates without any other abnormal finding from the respiratory system were allowed to enrol into the present study.

\section{Methods}

\section{Data collection}

An invitation to participate in the project, together with a questionnaire, was administered by the ward staff as the mother entered the ward with her newborn infant. Enrolment in the study occurred after signed informed consent was obtained from the mother and also the father, if he was present. The study was approved by the regional Medical Ethics Committee. A registration form for 
each infant was completed by the ward secretary, containing data on health of the infant and mother during the pregnancy (maternal diseases, cigarette smoking, drug or alcohol consumption) and postnatal health of the infant (gestational age according to last menstrual period and by maturity evaluation by the paediatrician, birth weight, birth length, Apgar score, and possible clinical problems during the time from birth to discharge from the hospital). As the infants were weighed routinely only at birth and on day 4 (discharge day), birth weight was used for analysis.

\section{Measurements}

Tidal breathing parameters were measured as close to day 2 and day 3 of life as possible, as lung function seem to change the least during this period of the first five days of life [5]. All infants were measured awake, quietly resting in the investigators lap in the left semi-lateral position, as this was the most practical way to hold the baby whilst working the lung function testing equipment. If the infants fell asleep, they were gently awakened before completion of the test. If the infant was uncooperative, the infant was given a few drops of water or breast-fed, and measurements were performed subsequently. Criteria for the awake state were: eyes open during parts of the test, spontaneous limb movements and/or active bodily movements as a response to stimulation. Measurements were performed by only one investigator in all but approximately 10 infants, who were tested by one other investigator.

Measurements of TFV loops and single-breath passive exhalation parameters were performed with the Sensor-

a)

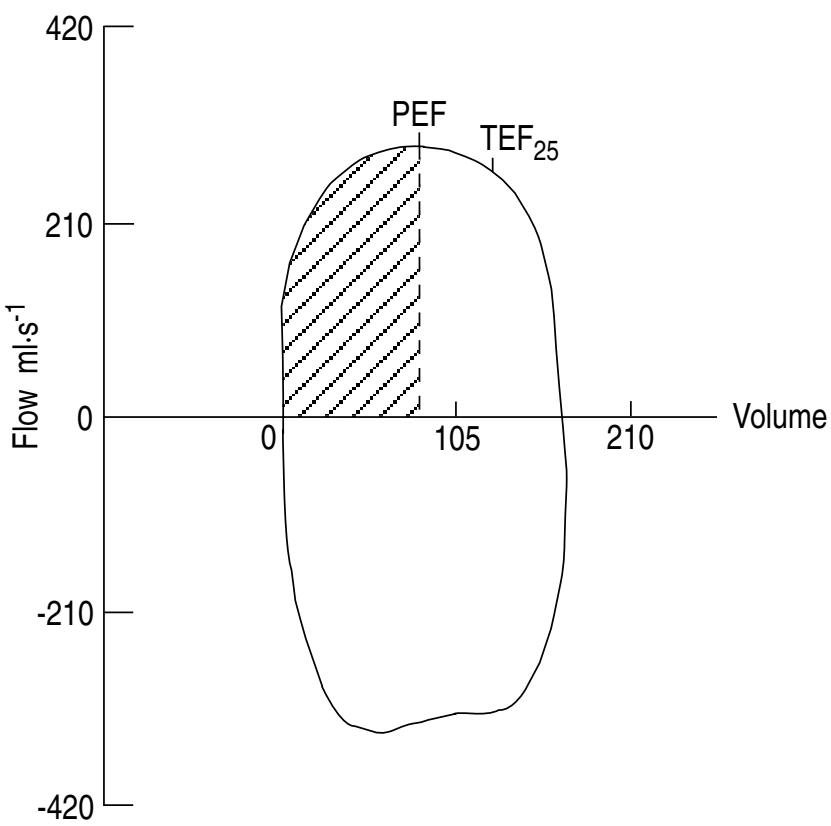

medics 2600 system. This system has been described in detail previously [5]. It consists of an IBM-PS2/50Z (80286) computer with an outboard microprocessor controlled (8085) analog-to-digital conversion module. A pneumotachograph (8311 series, Hans Rudolph, Missouri, USA) with a flow range of $0-10 l \cdot \mathrm{min}^{-1}$ was used for flow measurements. Volume was derived by the digital integration of the flow signal, which occurred at a sampling frequency of 256 samples $\cdot \mathrm{s}^{-1}$. A close-fitting face-mask (size 2) with an air-inflated cuff to ensure that no leaks occurred (Vital Signs inc.) was connected to the pneumotachograph. The dead space of the system was $2.4 \mathrm{ml}$, and that of the face mask was approximately $8.5-11 \mathrm{ml}$.

Calibration of the flow and volume signals was performed daily, using a $100 \mathrm{ml}$ precision syringe (Hans Rudolph). The system digitally integrated the flow signal at a rate exceeding 250 samples $\cdot \mathrm{s}^{-1}$, so that adjustments to the volume gain were correct adjustments for the flow signal also. A secondary step in the calibration process provided for a correction for alinearity and asymmetry in the pneumotachograph, valve, tubing and transducer system, with a 128 point linearization reference table.

\section{Lung function index calculation}

The index of ratio of time until peak flow to total expiratory time (TPEF/TE) was calculated by separate measurements of the time to peak expiratory flow and total expiratory time by the computer, at a sampling frequency in excess of $250 \cdot \mathrm{s}^{-1}$. The volume until peak flow to total expiratory volume (VPEF.VE) was calculated by the computer finding the highest flow after sorting through the flow and volume pairs. The volume exhaled

b)

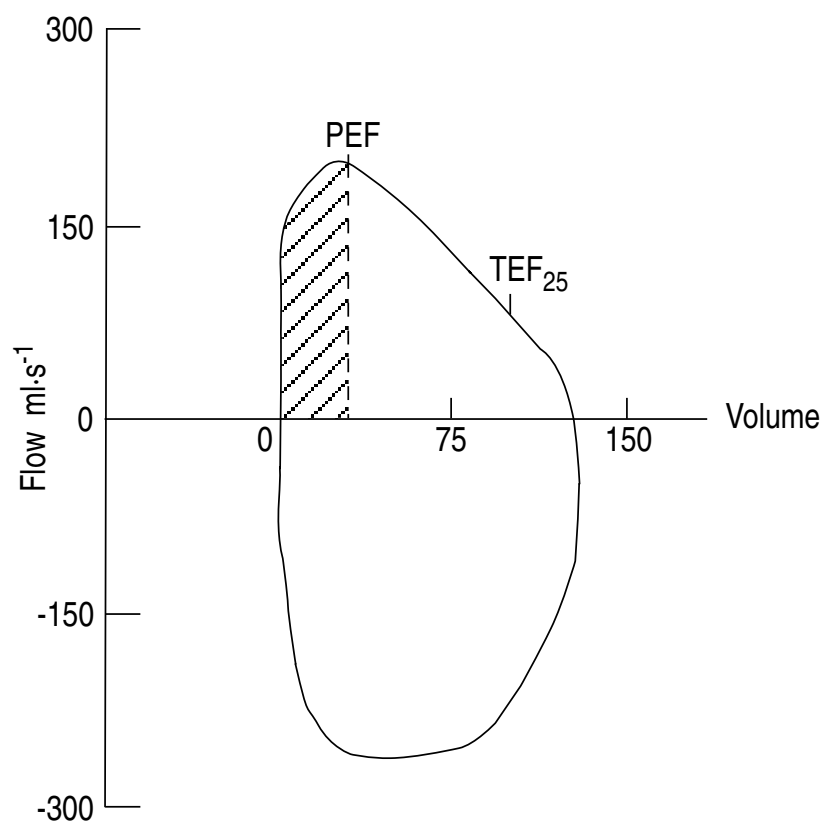

Fig. 1. - Tidal breathing expiratory parameters from tidal flow/volume loops (TFV). The two curves are taken from one patient: a) with no bronchopulmonary obstruction; and b) with bronchopulmonary obstruction. The important indices are, TPEF/TE: the ratio of time until peak flow to total expiratory time; $\mathrm{VPEF} / \mathrm{VE}$ : the ratio of volume until peak flow to total expiratory volume; $\mathrm{TEF}_{25} / \mathrm{PEF}$ : the ratio of expiratory flow at remaining $25 \%$ of expiration to flow at peak expiration. The two figures visualize the differences in ratios depending upon the shape of the curves, as seen by the sketched area. 
until peak flow, was calculated as a percentage of the total exhaled volume. The indices are shown in figure 1 .

Respiratory system mechanics were measured by the single-breath, passive occlusion technique, in accordance with generally recommended guidelines [1]. Automatic occlusion of the airway was initiated with the system's pneumatic slide valve (after the operator pressed a footswitch during an appropriate inspiration) at end-inspiration, following several breaths to establish a stable baseline. Time for closure of the valve depended on several factors, including system operating pressure, gas composition, and lubrication of the valve; and ranging 40-150 ms. Alveolar pressure $(\mathrm{PA})$ was thus recorded. Baseline was determined by the end-expiratory level of each breath, visually seen first during real time volume and flow to time trace, and subsequently by a stored picture with volume to time trace. If a visual drift in baseline occurred, the curve was manually rejected [5], but no mathematical acceptance limit was defined. Occlusion was maintained until relaxation of the respiratory system against the shutter, and equilibration of the alveolar and airway pressure was verified by the computer recording a plateau pressure within $\pm 0.125 \mathrm{cmH}_{2} \mathrm{O}$ for $100 \mathrm{~ms}$. The passive exhalation flow-volume loops obtained upon slide valve opening, were stored and used for calculation. A linear segment, late in the decelerating flow-volume curve, was selected and a least-squares best-fit line was drawn and extended to cross the volume axis at zero flow and the flow axis at zero volume. This was manually checked, and if necessary corrected by visual best-fit of linearity of the curve. Respiratory system compliance (Crs) was calculated from the volume intercept and plateau pressure using the formula: $\mathrm{Crs}=$ expired volume/PA. The resistance of the respiratory system (Rrs) was calculated from the flow intercept and plateau pressure according to the formula: Rrs=time constant/Crs [7].

Four representative TFV loops were stored for analysis. Each loop was chosen from eight stored loops obtained from a series of breaths during established tidal breathing (four stored in the computer and the last four breaths). The curves were selected from tidal breaths with as stable volume and shape of the loops as possible, and the respiratory rate being as low as possible. The results given for each child are the mean of these four curves. The reported respiratory rate is based upon the mean of the rates calculated for each of the four stored breaths.

The results of the single-breath, passive occlusion measurements are the mean of the accepted curves obtained in each test. Curves with irregular pressure plateaus, or where a best-fit line could not be placed, were excluded from analysis. A mean of four (range 2-14) passive occlusion curves was stored for analysis.

\section{Statistical Analysis}

Within subject (intra individual) variation is given as coefficient of variation (CV) based upon the four curves sampled for each individual. Between subject (interindividual) variation is given as $\mathrm{CV}$ and as standard deviation (SD) of the results of all infants.
Bivariate correlation analysis was performed to define the relationship between the lung function parameters and each of the following characteristics of the infants: birth weight, length, gestational age, postnatal age, as well as respiratory rate and time since last feed was given. Stepwise multiple regression analysis was used to determine the relationship between the lung function parameters and all the infant characteristics described as above, as well as gender. Percentiles were calculated and presented according to the characteristic with the strongest association to the variable in question. Nonparametric tests (Wilcoxon rank sum test) were performed to detect possible differences in lung function parameters related to postnatal age and gender. Differences were considered statistically significant with a p-value equal to or below $5 \%$, and all tests were performed with two tails. Percentile charts were made in Harvard graphics, and the smoothing technique of percentile lines was ad modum Harvard Graphic.

\section{Results}

Table 2 shows mean values, standard deviations and minimum and maximum values (range) for the continuous dependent and independent variables included in the subsequent regression analyses.

\section{Inter- and intrasubject variation}

The inter- and intrasubject variability of the lung function parameters are given in table 3 . There was considerable variability in the lung function among all the infants. The highest intersubject variability was found in the passive occlusion measurements. Even though the shape of the TFV loops tended to vary in many infants, reproducible patterns of the curves were found in most infants.

\section{Multiple regression analyses}

Multiple regressions of tidal volumes and tidal flows are given in table 4 as regression coefficient with 95 percent confidence interval $(95 \% \mathrm{CI})$.

Table 3. - Intra- and interindividual variation in tidal breathing parameters in newborn awake infants

\begin{tabular}{lcc}
\hline & $\begin{array}{c}\text { Intra-individual } \\
\text { variation CV\% }\end{array}$ & $\begin{array}{c}\text { Interindividual } \\
\text { variation CV\% }\end{array}$ \\
\hline $\mathrm{VT}$ & 6.3 & 18.4 \\
$\mathrm{PEF}$ & 13.9 & 26.3 \\
$\mathrm{TEF}_{50}$ & 14.9 & 27.3 \\
$\mathrm{TPEF} / \mathrm{TE}$ & 18.1 & 35.4 \\
$\mathrm{VPEF} / \mathrm{VE}$ & 16.1 & 28.2 \\
$\mathrm{TEF}_{25} / \mathrm{PEF}$ & 10.1 & 15.1 \\
$\mathrm{Crs}$ & 17.8 & 28.7 \\
$\mathrm{Rrs}$ & 23.1 & 63.7 \\
\hline
\end{tabular}

Analysis of coefficient variation $(\mathrm{CV})$ as a measure of intrasubject variation is based upon four tidal breathing curves and a mean of 4.2 passive occlusion measurements in each infant. Between subject variation (interindividual) variation is given as $\mathrm{CV}$ of the mean from all infants. For abbreviations see legend to table 2 . 
Table 4. - Regression of lung function (expiratory volume, peak tidal expiratory flow (PEF) and mid-expiratory flow $\left(\mathrm{TEF}_{50}\right)$ on gender, birth weight, birth length, gestational age, age and respiratory rate in 803 healthy infants

\begin{tabular}{|c|c|c|c|c|c|c|}
\hline \multirow[b]{2}{*}{$\begin{array}{l}\text { Independent } \\
\text { variables }\end{array}$} & \multicolumn{2}{|c|}{ VT $(n=693)$} & \multicolumn{2}{|c|}{ PEF } & \multicolumn{2}{|c|}{$\mathrm{TEF}_{50}$} \\
\hline & $\begin{array}{l}\text { Regression } \\
\text { coefficient }\end{array}$ & $95 \% \mathrm{CI}$ & $\begin{array}{c}\text { Regression } \\
\text { coefficient }\end{array}$ & $95 \% \mathrm{CI}$ & $\begin{array}{c}\text { Regression } \\
\text { coefficient }\end{array}$ & $95 \% \mathrm{CI}$ \\
\hline Intercept & 5.9 & $-4.16-16.03$ & -33.0 & $-66.30-0.37$ & -0.41 & $-71.5--10.46$ \\
\hline Gender & -0.51 & $-1.10-0.08$ & $-2.18 *$ & $-4.13--0.23$ & $-2.61 *$ & $-4.40--0.82$ \\
\hline Age days & 0.29 & $-0.02-0.59$ & 0.75 & $-0.25-1.74$ & 0.21 & $-0.70-1.13$ \\
\hline Gestational age weeks & $0.25 *$ & $0.02-0.48$ & 0.46 & $-0.31-1.23$ & 0.46 & $-0.24-1.17$ \\
\hline Birth weight $\mathrm{kg}$ & $2.83 *$ & $2.06-3.60$ & $7.32 *$ & $4.78-9.86$ & $6.94 *$ & $4.62-9.27$ \\
\hline Birth length $\mathrm{cm}$ & $0.16^{*}$ & $0.03-0.29$ & 0.23 & $-0.20-0.07$ & 0.35 & $-0.05-0.74$ \\
\hline$f$ breaths $\cdot \mathrm{min}^{-1}$ & $-0.16^{*}$ & $-0.18--0.13$ & $0.76^{*}$ & $0.70-0.83$ & $0.77 *$ & $0.71-0.84$ \\
\hline
\end{tabular}

95\%CI: 95\% confidence interval. *: Denotes significant associations. For abbreviations see legend to table 2.

Tidal expiratory volume $\left(V_{T}\right)$. In bivariate analyses, respiratory rate was most closely associated with $\mathrm{V}_{\mathrm{T}}$ $(\mathrm{r}=0.40)$, followed by birth weight $(\mathrm{r}=0.30)$ and birth length $(\mathrm{r}=0.27)$.

In a stepwise, multiple regression, $\mathrm{r}^{2}$ was 0.32 when respiratory rate and birth weight were included, and did not increase further when all the other independent variables listed in table 4 were included. The table shows that the confidence intervals for the regression coefficients for gender and age span the null value, indicating that these variables are not significantly associated with VT.

Peak expiratory flow $(P E F)$. Again, respiratory rate was the independent variable which was most closely associated with PEF ( $r=0.66)$, followed by birth weight $(r=0.35)$ and postnatal age $(\mathrm{r}=0.32)$. The $\mathrm{r}^{2}$ in the multiple stepwise regression was 0.42 when respiratory rate alone was included, increasing to a maximum of 0.48 when including birth weight. No further increase in $\mathrm{r}^{2}$ was seen when including the remaining independent variables. However, the confidence intervals for the regression coefficients for gestational and postnatal age, as well as birth length, spanned the null value, and were not significantly associated with PEF.

Expiratory flow at $50 \%$ expiration $\left(T E F_{50}\right)$. As with PEF, respiratory rate was the independent variable which was most closely associated with $\mathrm{TEF}_{50}(\mathrm{r}=0.70)$, followed

Table 5. - Percentiles of tidal expiratory volume and flow parameters according to birth weight

\begin{tabular}{|c|c|c|c|c|c|c|c|c|c|c|}
\hline \multirow[b]{2}{*}{ Weight } & \multirow[b]{2}{*}{ Sex } & \multicolumn{9}{|c|}{ Percentiles } \\
\hline & & 2.5 & 5 & 10 & 25 & 50 & 75 & 90 & 95 & 97.5 \\
\hline \multicolumn{11}{|l|}{$\begin{array}{ll}\text { VT } \\
\mathrm{ml}\end{array}$} \\
\hline \multirow[t]{2}{*}{$2.00-2.99 \mathrm{~kg}$} & M & 13.2 & 14.9 & 17.1 & 19.8 & 21.8 & 24.4 & 27.3 & 29.0 & 29.9 \\
\hline & $\mathrm{F}$ & 15.7 & 17.1 & 18.2 & 19.6 & 21.9 & 24.1 & 26.2 & 29.5 & 31.0 \\
\hline \multirow{2}{*}{$3.00-3.49 \mathrm{~kg}$} & M & 17.5 & 18.5 & 19.3 & 21.5 & 23.6 & 26.8 & 30.4 & 33.1 & 35.7 \\
\hline & $\mathrm{F}$ & 16.9 & 17.5 & 19.1 & 20.5 & 23.1 & 26.3 & 28.8 & 31.0 & 32.0 \\
\hline \multirow[t]{2}{*}{$3.50-3.99 \mathrm{~kg}$} & M & 16.9 & 19.1 & 20.4 & 22.5 & 24.8 & 28.0 & 31.4 & 32.5 & 34.6 \\
\hline & $\mathrm{F}$ & 18.6 & 19.3 & 20.4 & 22.3 & 24.8 & 27.9 & 31.0 & 34.1 & 35.4 \\
\hline \multirow{2}{*}{$4.00-5.20 \mathrm{~kg}$} & M & 17.8 & 20.1 & 21.0 & 23.8 & 26.1 & 30.0 & 32.5 & 34.6 & 36.4 \\
\hline & $\mathrm{F}$ & 19.3 & 19.5 & 20.3 & 22.4 & 24.8 & 28.1 & 31.8 & 33.8 & 35.6 \\
\hline \multicolumn{11}{|l|}{ PEF $\mathrm{ml} \cdot \mathrm{s}^{-1}$} \\
\hline \multirow[t]{2}{*}{$2.00-2.99 \mathrm{~kg}$} & M & 13.2 & 14.9 & 17.1 & 19.8 & 21.8 & 24.4 & 27.3 & 29.0 & 29.9 \\
\hline & $\mathrm{F}$ & 15.7 & 17.1 & 18.2 & 19.6 & 21.9 & 24.1 & 26.2 & 29.5 & 31.0 \\
\hline \multirow[t]{2}{*}{$3.00-3.49 \mathrm{~kg}$} & M & 17.5 & 18.5 & 19.3 & 21.5 & 23.6 & 26.8 & 30.4 & 33.1 & 35.7 \\
\hline & $\mathrm{F}$ & 16.9 & 17.5 & 19.1 & 20.5 & 23.1 & 26.3 & 28.8 & 31.0 & 32.0 \\
\hline \multirow{2}{*}{$3.50-3.99 \mathrm{~kg}$} & M & 16.9 & 19.1 & 20.4 & 22.5 & 24.8 & 28.0 & 31.4 & 32.5 & 34.6 \\
\hline & $\mathrm{F}$ & 18.6 & 19.3 & 20.4 & 22.3 & 24.8 & 27.9 & 31.0 & 34.1 & 35.4 \\
\hline \multirow[t]{2}{*}{$4.00-5.20 \mathrm{~kg}$} & M & 17.8 & 20.1 & 21.0 & 23.8 & 26.1 & 30.0 & 32.5 & 34.6 & 36.4 \\
\hline & $\mathrm{F}$ & 19.3 & 19.5 & 20.3 & 22.4 & 24.8 & 28.1 & 31.8 & 33.8 & 35.6 \\
\hline \multicolumn{11}{|l|}{$\mathrm{TEF}_{50} \mathrm{ml} \cdot \mathrm{s}^{-1}$} \\
\hline \multirow[t]{2}{*}{$2.00-2.99 \mathrm{~kg}$} & M & 13.2 & 14.9 & 17.1 & 19.8 & 21.8 & 24.4 & 27.3 & 29.0 & 29.9 \\
\hline & $\mathrm{F}$ & 15.7 & 17.1 & 18.2 & 19.6 & 21.9 & 24.1 & 26.2 & 29.5 & 31.0 \\
\hline \multirow[t]{2}{*}{$3.00-3.49 \mathrm{~kg}$} & M & 17.5 & 18.5 & 19.3 & 21.5 & 23.6 & 26.8 & 30.4 & 33.1 & 35.7 \\
\hline & $\mathrm{F}$ & 16.9 & 17.5 & 19.1 & 20.5 & 23.1 & 26.3 & 28.8 & 31.0 & 32.0 \\
\hline \multirow[t]{2}{*}{$3.50-3.99 \mathrm{~kg}$} & M & 16.9 & 19.1 & 20.4 & 22.5 & 24.8 & 28.0 & 31.4 & 32.5 & 34.6 \\
\hline & $\mathrm{F}$ & 18.6 & 19.3 & 20.4 & 22.3 & 24.8 & 27.9 & 31.0 & 34.1 & 35.4 \\
\hline \multirow[t]{2}{*}{$4.00-5.20 \mathrm{~kg}$} & M & 17.8 & 20.1 & 21.0 & 23.8 & 26.1 & 30.0 & 32.5 & 34.6 & 36.4 \\
\hline & $\mathrm{F}$ & 19.3 & 19.5 & 20.3 & 22.4 & 24.8 & 28.1 & 31.8 & 33.8 & 35.6 \\
\hline
\end{tabular}

For abbreviations see legend to table 2 . 

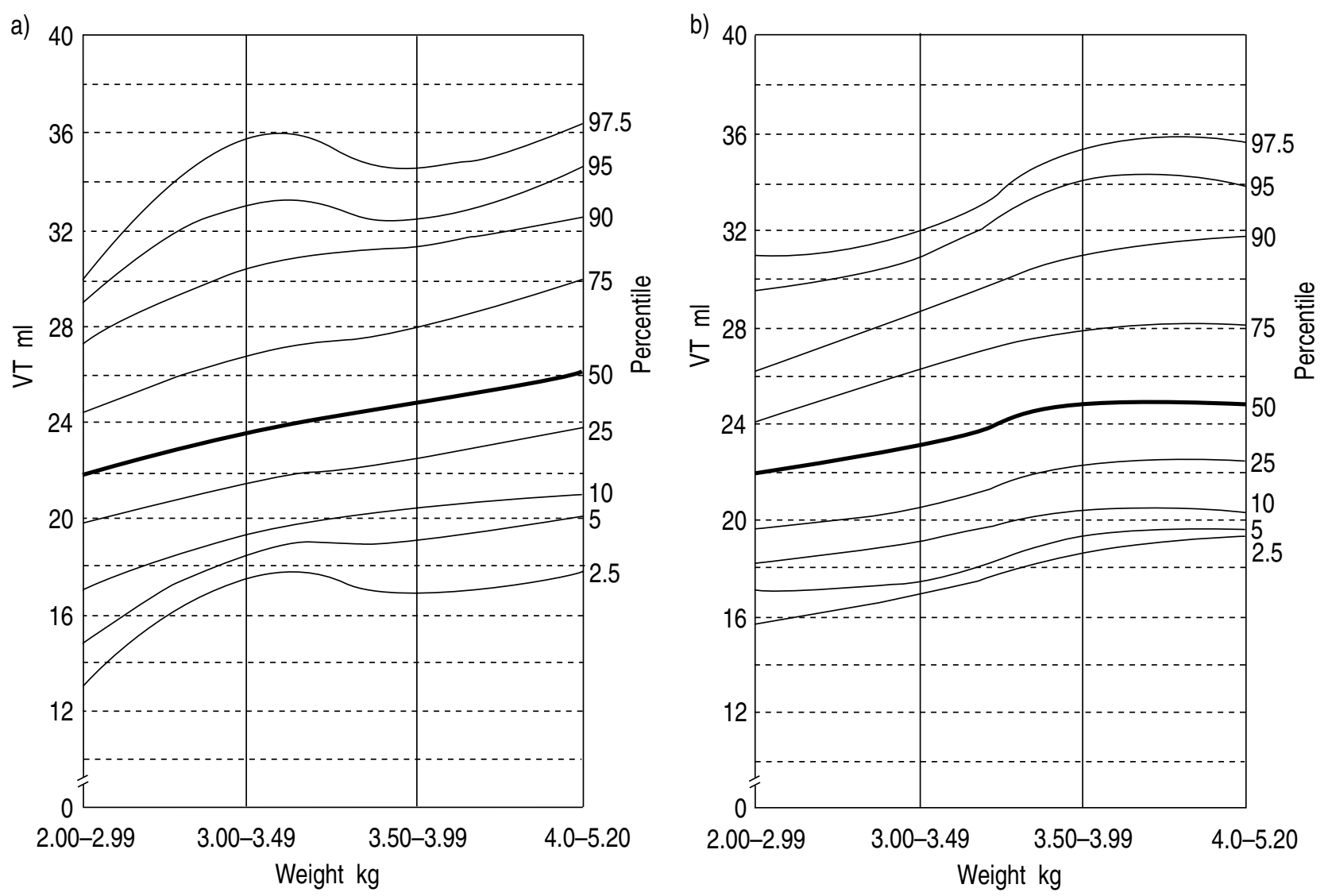

Fig. 2. - Tidal volume ( $\left.\mathrm{V}_{\mathrm{T}}\right)$ presented as percentiles according to weight group for: a) males; and b) females. The $50^{\text {th }}$ percentile is thickened for emphasis.

by birth weight $(\mathrm{r}=0.37)$. Stepwise multiple regression gave an $\mathrm{r}^{2}$ of 0.46 with only respiratory rate included, increasing to 0.53 when including birth weight, and with a further marginal increase to 0.54 when including gender. Gestational and postnatal age, as well as birth length, were not significantly associated with tidal midexpiratory flow.

Flow ratios. The $\mathrm{r}^{2}$ in a multiple regression analysis of $\mathrm{TPEF} / \mathrm{TE}, \mathrm{VPEF} / \mathrm{VE}$ and $\mathrm{TEF}_{25} / \mathrm{PEF}$ did not exceed 0.06 when all the independent variables were included in the model. No definition of a regression equation for these parameters was, therefore, attempted.

\section{Percentiles}

$\mathrm{V}_{\mathrm{T}}$ (given as expiratory volume) and tidal flows are shown in table 5 and in figure $2(\mathrm{VT})$ as percentiles. As birth weight was the infant characteristic most strongly associated with expiratory volume and tidal flows, percentiles were calculated according to weight classes arbitrarily chosen at $500 \mathrm{~g}$ intervals. Due to the low number of subjects below $3 \mathrm{~kg}$ and above $4 \mathrm{~kg}$, infants were grouped in the weight categories: $2.0-2.99 \mathrm{~kg}$; $3.0-3.49 \mathrm{~kg} ; 3.5-3.99 \mathrm{~kg} ; 4 \mathrm{~kg}$ and above. Furthermore, gender was significantly associated with tidal flows, and the results are, therefore, presented according to gender for each weight group.

\section{Tidal flow ratios}

The flow ratios TPEF/TE, VPEF/VE and $\mathrm{TEF}_{25} / \mathrm{PEF}$ were significantly higher in two compared to three day old infants $(p<0.005)$, but were highest in the 1 day old infants (medians for all infants $0.39,0.46$ and 0.81 respectively). No significant differences in these ratios were found in infants older than three days, but borderline significantly higher TPEF/TE was found in three compared to four day old infants $(p=0.054)$. The results of the flow ratios are, therefore, presented as percentiles according to postnatal age, in table 6 , and similarily as percentiles for males and females in figure 3 for TPEF/TE. Due to the low number of infants in the highest age groups, all infants four days and older are presented as one group. The flow ratios were higher in males than in females $(p<0.03)$ when analysing all infants together according to gender.

\section{Respiratory mechanics}

Mean Crs per kg weight was 1.18 (95\% CI 1.15-1.21) $\mathrm{ml} \cdot \mathrm{cmH}_{2} \mathrm{O}^{-1} \cdot \mathrm{kg}$ for all infants $(\mathrm{n}=664)$. A significant inverse correlation was found between respiratory rate and $\mathrm{Crs}(\mathrm{r}=-0.52 ; \mathrm{p}<0.001)$.

Mean Rrs was 0.051 (95\% CI 0.048-0.053) $\mathrm{cmH}_{2} \mathrm{O} \cdot \mathrm{ml}^{-}$ ${ }^{1}$.s. Although Rrs tended to decrease with increasing weight, and increase with increasing age $(p<0.001)$, the associations were very weak, with a correlation coefficient of -0.12 and 0.12 , respectively, employing bivariate analysis. No significant differences in Rrs related to gender were found. 
Table 6. - Tidal flow ratio according to postnatal age (days)

\begin{tabular}{|c|c|c|c|c|c|c|c|c|c|c|c|}
\hline $\begin{array}{l}\text { Age } \\
\text { days }\end{array}$ & $\mathrm{n}$ & Sex & 2.5 & 5 & 10 & 25 & $\begin{array}{c}\text { Percentiles } \\
50\end{array}$ & 75 & 90 & 95 & 97.5 \\
\hline TPEF & & & & & & & & & & & \\
\hline 1 & 8 & $\mathrm{M}$ & 0.21 & 0.21 & 0.21 & 0.27 & 0.39 & 0.46 & & & \\
\hline & 13 & $\mathrm{~F}$ & 0.08 & 0.08 & 0.16 & 0.29 & 0.41 & 0.43 & 0.49 & & \\
\hline 2 & 191 & M & 0.16 & 0.18 & 0.21 & 0.27 & 0.36 & 0.43 & 0.48 & 0.54 & 0.63 \\
\hline & 161 & $\mathrm{~F}$ & 0.13 & 0.16 & 0.20 & 0.26 & 0.31 & 0.38 & 0.47 & 0.51 & 0.52 \\
\hline 3 & 164 & $\mathrm{M}$ & 0.12 & 0.14 & 0.18 & 0.23 & 0.30 & 0.37 & 0.43 & 0.51 & 0.56 \\
\hline & 153 & $\mathrm{~F}$ & 0.12 & 0.14 & 0.16 & 0.22 & 0.28 & 0.35 & 0.44 & 0.47 & 0.52 \\
\hline 4-9 & 61 & M & 0.10 & 0.14 & 0.16 & 0.20 & 0.27 & 0.32 & 0.41 & 0.43 & 0.53 \\
\hline & 46 & $\mathrm{~F}$ & 0.08 & 0.10 & 0.14 & 0.20 & 0.27 & 0.35 & 0.39 & 0.47 & 0.51 \\
\hline VPEF & & & & & & & & & & & \\
\hline 1 & 8 & $\mathrm{M}$ & 0.28 & 0.28 & 0.28 & 0.34 & 0.46 & 0.57 & & & \\
\hline & 13 & $\mathrm{~F}$ & 0.13 & 0.13 & 0.15 & 0.35 & 0.45 & 0.55 & 0.56 & & \\
\hline 2 & 191 & M & 0.21 & 0.24 & 0.26 & 0.32 & 0.40 & 0.47 & 0.53 & 0.57 & 0.62 \\
\hline & 161 & $\mathrm{~F}$ & 0.19 & 0.21 & 0.26 & 0.32 & 0.37 & 0.43 & 0.51 & 0.54 & 0.58 \\
\hline 3 & 161 & M & 0.16 & 0.21 & 0.23 & 0.29 & 0.37 & 0.43 & 0.49 & 0.55 & 0.60 \\
\hline & 153 & $\mathrm{~F}$ & 0.19 & 0.21 & 0.23 & 0.27 & 0.33 & 0.41 & 0.49 & 0.50 & 0.57 \\
\hline $4-9$ & 61 & M & 0.14 & 0.18 & 0.22 & 0.27 & 0.32 & 0.38 & 0.47 & 0.49 & 0.60 \\
\hline & 46 & $\mathrm{~F}$ & 0.15 & 0.18 & 0.22 & 0.28 & 0.33 & 0.39 & 0.47 & 0.49 & 0.54 \\
\hline TEF & & & & & & & & & & & \\
\hline 1 & 8 & M & 0.61 & 0.61 & 0.61 & 0.67 & 0.79 & 0.83 & & & \\
\hline & 13 & $\mathrm{~F}$ & 0.50 & 0.50 & 0.52 & 0.69 & 0.85 & 0.88 & 0.90 & & \\
\hline 2 & 191 & M & 0.54 & 0.56 & 0.63 & 0.72 & 0.78 & 0.84 & 0.90 & 0.91 & 0.94 \\
\hline & 161 & $\mathrm{~F}$ & 0.48 & 0.56 & 0.61 & 0.69 & 0.77 & 0.82 & 0.88 & 0.90 & 0.92 \\
\hline 3 & 164 & M & 0.50 & 0.55 & 0.60 & 0.69 & 0.77 & 0.82 & 0.86 & 0.90 & 0.91 \\
\hline & 153 & $\mathrm{~F}$ & 0.47 & 0.48 & 0.54 & 0.65 & 0.74 & 0.81 & 0.86 & 0.89 & 0.92 \\
\hline $4-9$ & 61 & M & 0.51 & 0.55 & 0.59 & 0.65 & 0.72 & 0.80 & 0.83 & 0.85 & 0.92 \\
\hline & 46 & $\mathrm{~F}$ & 0.39 & 0.42 & 0.50 & 0.59 & 0.73 & 0.80 & 0.88 & 0.90 & 0.91 \\
\hline
\end{tabular}

a)

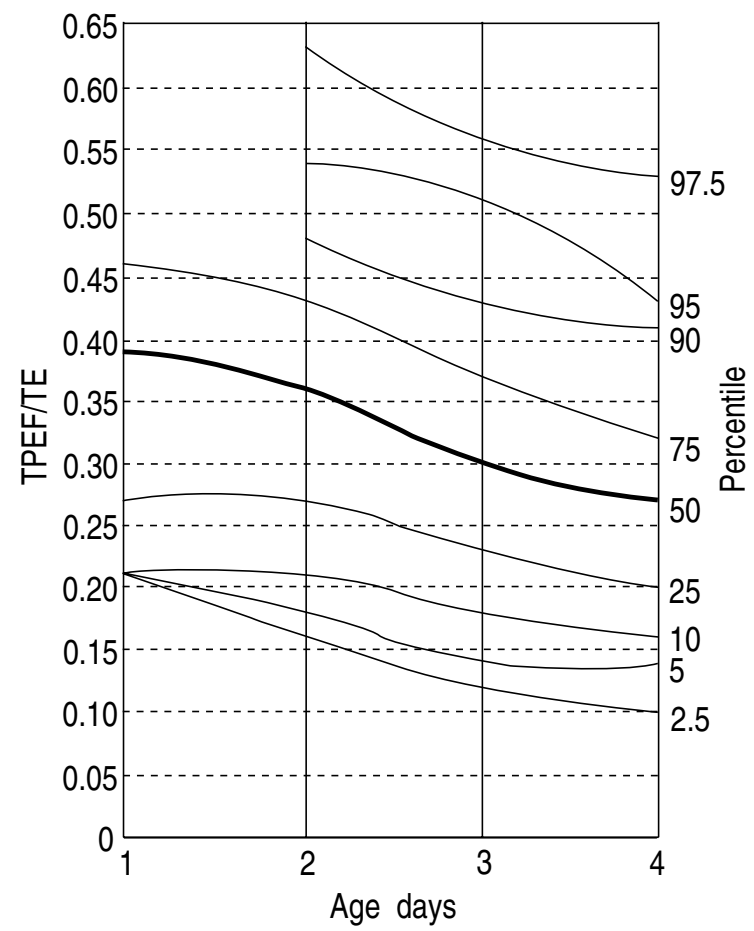

b)

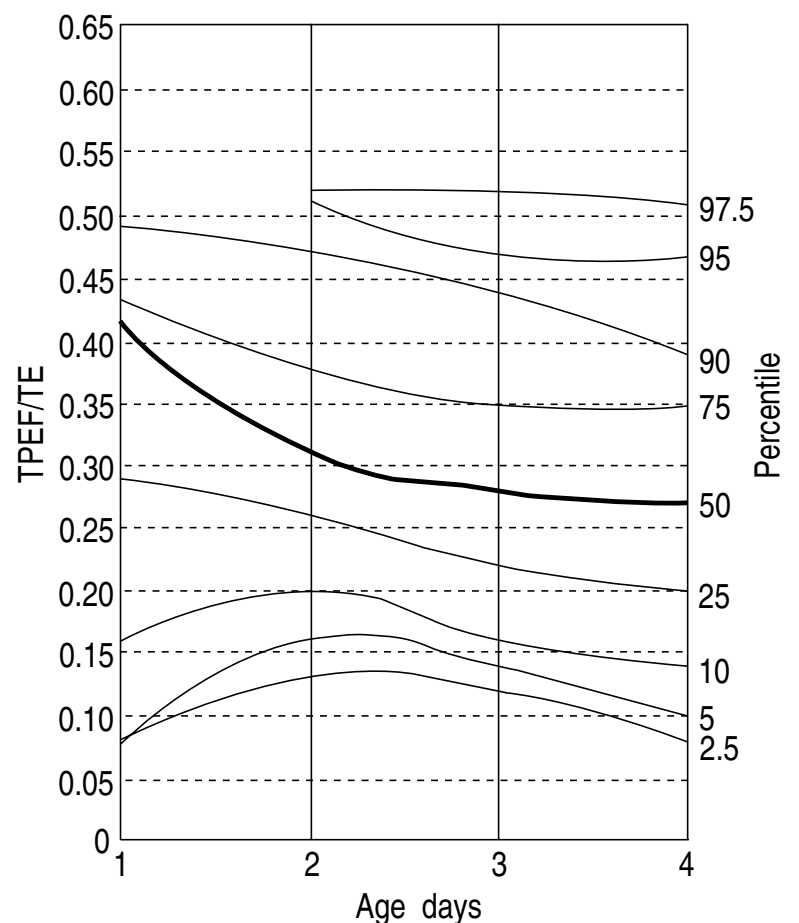

Fig. 3. - TPEF/Te presented as percentiles according to postnatal age for: a) males; and b) females. TPEF/TE: the ratio of time to reach peak flow to total expiratory time. The $50^{\text {th }}$ percentile is thickened for emphasis. 


\section{Multiple regression}

For Crs, the highest $\mathrm{r}^{2}$ obtained was 0.30 when all infant characteristics as well as respiratory rate and time since last feed were included. Leaving out respiratory rate, the $\mathrm{r}^{2}$ was only 0.05 . No regression model for Rrs could be determined, as $\mathrm{r}$ did not exceed 0.05 when including all the independent variables mentioned above.

\section{Discussion}

Measurement of tidal breathing lung function parameters in awake, healthy newborn infants demonstrated that $\mathrm{VT}_{\mathrm{T}}$ was not influenced by gender after weight adjustment; whereas, tidal flows and flow ratios were significantly higher in males than in females. Flow ratios were significantly higher in two than three day old infants, but no significant differences related to age was found after three days of age. Resistance of the respiratory system, but not Crs tended to increase with increasing age of the infant.

No significant correlation was found between respiratory rate and tidal flow ratios. Gestational age within the limits of the inclusion criteria and time since feeding did not influence any of the observed lung function parameters.

The present study reports values of a higher number of subjects than in previous studies, and within a narrow age and size span. The results are presented as percentiles for tidal volume and tidal flows and flow ratios, and as regression models for reference values when a reasonable association between dependent and independent variables was found, as recommended by QUANJER et al. [2]. Gender specific data were presented, as it has been reported that lung function may differ according to gender in young children [8].

Tidal volume in the present study is in agreement with that of other studies [5, 9], and the increase with increasing birth weight has previously been recognized [1]. However, the subjects in most studies evaluating tidal volume have been older than the subjects in the present study, and thus tidal volume has been larger [3] (around $30 \mathrm{ml}$ for infants between 40-50 postconceptional weeks). Peak tidal expiratory flow in the present study was higher than that described by HANRAHAN et al. [3] in older infants (mean 54.7 \pm 17.2 (SD) for females and $59 \pm 15.0$ for males), as was $\mathrm{TEF}_{50}$ (in their study $50.1 \pm 15.5$ and $52.6 \pm 14.5$ for females and males, respectively). This may be explained by arousal state, as awake infants seem to have higher tidal flows than sleeping infants, as shown previously [4]. However, considering intersubject variability in these two studies ([3] and the present study), $95 \%$ of our infants had values within \pm 2 SD of their results.

There are few reports in neonates of reference values for tidal flow ratios, as reported in the present study. However, the presently observed decrease in TPEF/TE with increasing age during the first few days of life is supported by the findings of FISHER et al. [10]. With the large number of infants in the present study, a significant decline in TPEF/TE with increasing age to the third day of life was demonstrated. A similar trend was shown in a previous longitudinal study of 24 infants [5] measured during their five first days of life. The mean Tpef/Te
(0.32) in the present study was slightly larger than previously reported by us $[4,5]$, but smaller than that

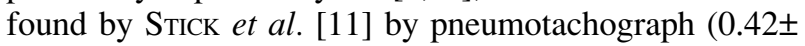
0.14). The ratios $\mathrm{VPEF} / \mathrm{VE}$ and $\mathrm{TEF}_{25} / \mathrm{PEF}$ were within the same range as in our previous study [5], but we are not familiar with other published reports of these parameters.

The results of the passive occlusion measurements were well in agreement with previous studies employing the single-breath occlusion technique $[4,5,12,13]$. However, we could not determine any reasonable regression equation for Crs or Rrs, as was done by HAouzi et al. [13]. However, their infants ranged from 1.26 to $3.98 \mathrm{~kg}, 26-40$ weeks gestational age and 3-29 days of age, and they found weight as the size variable most closely associated with Crs and Rrs. We previously reported a small, but significant increase in Rrs related to postnatal age [5], and we are not familiar with similar findings in the literature.

Information on intra-individual variation of tidal flow ratios in newborn infants is limited [1], but a few reports on the within-subject variation of TPEF/TE exists, which are comparable to our results. In sleeping infants, STICK et al. [11] found a mean CV 17 of 13\% (range 6-21\%); GUPTA et al. [14] reported a CV of $13-14 \%$ and FisHER et al. [9] found a CV in the range $29-32 \%$ for the (equivalent to) TPEF/TE. The intra-individual variation of Crs $(17.8 \%)$ and $\operatorname{Rrs}(23.1 \%)$ in the present study is higher than that found by others: with a CV for Rrs from $11-15 \%$ [1], and slightly lower for Crs (Haouzi et al. [13]; 9.6 \pm 5.3 for Crs), but is approximately the same as we have reported previously [5].

The between subject (interindividual) variation in tidal volume and tidal flows is lower in the present study than that found by HANRAHAN et al. [3], but the number of individuals for comparison is different (803 in the present study versus 44 young infants in their study). Few reports on interindividual variation of flow ratios are published. However, the standard deviation of TPEF/TE in the present study is lower than that found by STICK et al. [11] of 0.14 in a study of 19 quietly sleeping individuals, but higher than that found in sleeping or sedated infants (2-14 weeks of age) of approximately 0.8 reported by MARTinEZ et al. [15].

The respiratory rate reported in the present study probably exceeds the actual respiratory rate in the infants. This may, in part, be related to some degree of hyperventilation. However, it may also be related to the limited number of curves stored for analysis, where the estimated respiratory rate for each of the four breaths constitutes the basis from which the respiratory rate is reported. This demonstrates one problem with sampling only four single breaths, even though they were preferentially stored from the same breathing sequence. Methodologically, it would be beneficial to analyse a larger number of sequential breaths, in retrospect.

The variability of tidal lung function measurements could only in part be explained by infant size, gender and postnatal age, but with no influence of gestational age or time since feeding upon lung function. The closest associations with size were found for tidal volume and tidal flows, with birth weight being by far the most 
important determinator. Furthermore, the larger tidal peak flow in boys in our study is in accordance with the findings of HANRAHAN et al. [3], who reported generally higher tidal flows in girls than in boys, but where in fact their results for tidal peak flow was reversed. Even though there was a significant association between the flow ratios and postnatal age, the explained variability was no more than $6 \%$. This indicates that the shape of the TFV curve is little influenced by the variability sources examined in the present study, and represents a stable measurement in healthy newborn infants. Measurements of parameters describing the shape of TFV curves may, therefore, be valuable in the follow-up in epidemiological studies. Stable values in healthy newborn infants may also suggest that such parameters may be valuable in assessment of respiratory illness in this age group. Furthermore, no association between respiratory rate and the flow ratios were found. As all infants were awake, as well as being positioned in the same way during measurement, we could not evaluate possible influence of arousal state or posture upon these ratios.

In the present study, tidal breathing parameters in newborn infants, without respiratory disease have been presented, with an evaluation of potential sources of variability and their strength of interaction. Measurements were possible to perform in all the infants awake, with intra- and interindividual variation comparable to studies in sleeping neonates. We believe that some of the concerns and questions in standardization of lung function [1] have been addressed in a controlled manner, showing that this simple noninvasive method can be used as an epidemiological tool.

Acknowledgement: The authors want to express gratitude to the staff at the delivery and maternity wards at Ullevål Hospital for their help and support in the project.

\section{References}

1. ATS-ERS statement. Respiratory mechanics in infants: physiologic evaluation in health and disease. Eur Respir $J$ 1993; 6: 279-310.

2. Quanjer PhH, Stocks J, Polgar G, Wise M, Karlberg J, Borsboom G. Compilation of reference values for lung function measurements in children. Eur Respir J 1989; 2 (Suppl. 4): 184s-261s.

3. Hanrahan JP, Tager IB, Castile RG, Segal R, Weiss ST, Speizer FE. Pulmonary function measures in healthy infants. Am Rev Respir Dis 1990; 141: 1127-1135.

4. Lødrup KC, Mowinckel P, Carlsen KH. Lung function measurements in awake compared to sleeping newborn infants. Pediatr Pulmonol 1992; 12: 99-104.

5. Lødrup Carlsen KC, Carlsen KH. Lung function in awake healthy infants in the five first days of life. Eur Respir $J$ 1993; 6: 1496-1500.

6. Dezateux CA, Fletcher ME, Rabbette PS, Stanger LJ, Stocks J. A manual of infant lung function testing (ISBN 095189560 5). London. Portex anaesthesia, Intensive Therapy and Respiratory Medicine Unit, Institute of Child Health, 1991.

7. Pfenninger J, Aebi C, Bachmann D, Wagner BP. Lung mechanics and gas exchange in ventilated preterm infants during treatment of hyaline membrane disease with multiple doses of artificial surfactant (Exosurf). Pediatr Pulmonol 1992; 14: 10-15.

8. Morgan WJ, Geller DE, Tepper RS, Taussig LM. Partial expiratory flow-volume curves in infants and young children. Pediatr Pulmonol 1988; 5: 232-243.

9. Fisher JT, Mortola JP, Smith B, Gordon SF, Weeks SK. Neonatal pattern of breathing following cesarean section: epidural versus general anesthesis. Anesthesiology 1983; 59: 385-389.

10. Fisher JT, Mortola JP, Smith JB, Fox GS, Weeks S. Respiration in newborns. Development of the control of breathing. Am Rev Respir Dis 1982; 125: 650-657.

11. Stick SM, Ellis E, LeSouef PN, Sly PD. Validation of respiratory inductance plethysmography (Respitrace) for the measurement of tidal breathing parameters in newborn. Pediatr Pulmonol 1992; 14: 187-191.

12. Mortola JP, Fisher JT, Smith B, Fox G, Weeks S. Dynamics of breathing in infants. J Appl Physiol: Respirat Environ Exercise Physiol 1982; 52: 1209-1215.

13. Haouzi P, Marchal JP, Crance P, Vert P. Respiratory mechanics in spontanously breathing term and preterm neonates. Biol Neonate 1991; 60: 350-360.

14. Gupta SK, Wagener JS, Erenberg A. Pulmonary mechanics in healthy term neonates: variability in measurements obtained with a computerized system. J Pediatr 1990; 117: 603-606.

15. Martinez FD, Morgan WJ, Wright AL, Holberg CJ, Taussig LM. Diminished lung function as a predisposing factor for wheezing respiratory illness in infants. N Engl J Med 1988; 319: 1112-1117. 